\title{
The Pan-AC assay: a single-reaction real-time PCR test for quantitative detection of a broad range of Aspergillus and Candida species
}

\author{
Lenka Bašková,† Christine Landlinger,† Sandra Preuner and Thomas Lion
}

Correspondence

Thomas Lion

Thomas.Lion@ccriat

Received 5 February 2007

Accepted 4 May 2007

\author{
Division of Molecular Microbiology and Development of Genetic Diagnostics, Children's Cancer \\ Research Institute, A-1090 Vienna, Austria
}

\section{INTRODUCTION}

Invasive fungal infections (IFIs) continue to represent a significant problem in immunosuppressed individuals. It has been estimated that more than $90 \%$ of all IFIs are caused by Aspergillus and Candida species (Beck-Sagué \& Jarvis, 1993; Goodrich et al., 1991; Singh, 2001; Vincent et al., 1998). Early detection of the fungal pathogen is crucial for appropriate antifungal therapy and thus the clinical outcome of patients with IFI (Morace et al., 1997). Conventional diagnostic tests, including blood cultures (Duthie \& Denning, 1995; Vincent et al., 1998) and serological detection of circulating fungal antigens (e.g. Dglucan or galactomannan) (Pfeiffer et al., 2006), have shown variable sensitivity and specificity. Histological

†These authors contributed equally to this work.

Abbreviations: $\mathrm{C}_{\mathrm{T}}$, cycle threshold; EORTC, European Organization for Research and Treatment of Cancer; gDNA, genomic DNA; IFI, invasive fungal infection; Pan-AC, pan-Aspergillus and pan-Candida; RQ-PCR, real-time quantitative PCR; UNG, uracil N'-glycosylase. analyses of computed tomography-guided biopsies are highly sensitive and specific, but are frequently associated with bleeding complications in patients with severe thrombocytopenia (Denning, 1998). Therefore, efforts are ongoing to develop less invasive, yet reliable, sensitive and specific diagnostic tests for IFIs to overcome the limitations of the traditional fungus detection methods. Recently, a variety of PCR-based methods have been developed for rapid and sensitive detection of fungal pathogens (Chryssanthou et al., 1994; Einsele et al., 1997; Jordan, 1994; Sandhu et al., 1995). Since non-albicans Candida spp. and non-fumigatus Aspergillus spp. are increasing in importance (Bille et al., 2005; Coleman et al., 1998; Torres et al., 2003), diagnostic approaches covering a large number of fungal species are required. Broad-spectrum PCR methods mostly exploit the highly conserved regions of the ribosomal multi-copy rDNA gene cluster to amplify numerous fungal strains by a universal primer set (Medlin et al., 1988).

A considerable amount of data is available on the detection of IFIs using real-time quantitative PCR (RQ-PCR) 
approaches; however, a lot of published assays only permit detection of single fungal species (Costa et al., 2001; Loeffler et al., 2000; Spiess et al., 2003). To date, some TaqMan RQ-PCR methods covering either multiple Candida (Maaroufi et al., 2004; White et al., 2003) or Aspergillus species (Costa et al., 2002; Kami et al., 2001) are available. Earlier studies relying on LightCycler technology have demonstrated the principle feasibility of detecting moulds and yeasts in a single reaction (Jordanides et al., 2005; Klingspor \& Jalal, 2006). Our assay, however, is based on TaqMan technology employing a short universal hydrolysis probe localized within a highly conserved fungal region, which minimizes the effect of point mutations on the detectability of the fungal species. Based on comprehensive sequence analysis of the fungal $28 \mathrm{~S}$ rDNA genes, we have been able to establish an assay permitting the detection and monitoring of at least nine clinically relevant Candida species and six Aspergillus species. Our panAspergillus and pan-Candida assay (Pan-AC assay; patent pending) permits economic fungus screening and accurate quantification of a broad range of pathogenic Aspergillus and Candida species in the clinical setting.

\section{METHODS}

Fungal strains, bacteria and virus isolates. Fungal strains for PCR testing were obtained from the American Type Culture Collection (ATCC) and from the German Collection of Micro-organisms (DSM, Germany): A. fumigatus (ATCC 36607), Aspergillus niger (ATCC 10535), C. albicans (ATCC 14053), Candida dubliniensis (ATCC MYA646), Candida glabrata (ATCC 2001), Candida krusei (ATCC 6258), Candida parapsilosis (ATCC 22019) and Candida tropicalis (ATCC 750), and Aspergillus flavus (DSM 818), Aspergillus nidulans (DSM 820), Aspergillus terreus (DSM 826), Aspergillus versicolor (DSM 1943), Candida guilliermondii (DSM 70051), Candida kefyr (DSM 70073) and Candida lusitaniae (DSM 70102). Prior to DNA extraction, the fungal isolates were cultured on Sabouraud dextrose agar at $30{ }^{\circ} \mathrm{C}$; Candida isolates were cultured for $48 \mathrm{~h}$ and Aspergillus isolates for $72 \mathrm{~h}$. Suspensions of all fungi (Candida species, cell suspension; Aspergillus species, conidia suspension) were prepared using an aliquot of cultured fungus resuspended in sterile $0.9 \% \mathrm{NaCl}$ solution.

In addition, a panel of bacterial and viral micro-organisms were selected for testing of cross-reactivity. The panel included Enterobacter aerogenes, Eschericha coli, Haemophillus influenzae, Listeria monocytogenes, Pseudomonas aeruginosa, Salmonella enteritidis, Staphylococcus aureus, Streptococcus pneumoniae, Proteus vulgaris, human adenoviruses, Epstein-Barr virus, cytomegalovirus, varicella-zoster virus, herpes simplex virus types 1 and 2, and parvovirus B19 (PVB19).

Clinical materials. The clinical specimens from patients with documented fungus infections were obtained upon informed consent. The specimens included biopsies of pulmonary infiltrations $(n=2)$ and peripheral blood $(n=3)$ from haemato-oncological patients, bronchotracheal secretions $(n=11)$ from intensive care patients, and a cornea control specimen with a culture-documented infection by Fusarium solanii, which is outside the detection spectrum of the PanAC assay (kindly provided by St Anna Children's Hospital, Vienna, Austria and the Institute of Hygiene and Medical Microbiology, Medical University of Vienna, Austria). Peripheral blood specimens from healthy volunteer donors were used to test for cross-reactivity with human DNA.
DNA extraction. All steps were performed in a laminar flow hood. Reagents used for extraction were filtered through $0.2 \mu \mathrm{m}$ sterile filters.

(i) Fungal strains. A colony of each fungus culture was homogenized in $500 \mu \mathrm{l}$ lyticase lysis buffer (LLB) [50 mM Tris ( $\mathrm{pH} 7.6), 1 \mathrm{mM}$ EDTA (pH 8.0), 0.2\% 2-mercaptoethanol, $10 \mathrm{U} \mathrm{ml}^{-1}$ recombinant lyticase (Sigma)] and incubated at $37{ }^{\circ} \mathrm{C}$ for $1 \mathrm{~h}$. After incubation, acid-washed glass beads $710-1180 \mu \mathrm{m}$ in diameter (Sigma) were added and vortexed thoroughly for $2 \mathrm{~min}$. A total of $400 \mu \mathrm{l}$ supernatant were used for DNA extraction on a MagNA Pure compact instrument using the MagNA Pure compact nucleic acid isolation kit I (Roche Diagnostics) as described by the manufacturer. The DNA was eluted in a total volume of $100 \mu$ l elution buffer (Roche Diagnostics). DNA concentrations were determined by a PicoGreen dsDNA quantification kit (Molecular Probes) and fluorescence spectrophotometer F-2500 (Hitachi).

(ii) Blood specimens. After hypotonic lysis of the erythrocytes from $3 \mathrm{ml}$ blood using red cells lysis buffer [10 mM Tris ( $\mathrm{pH} 7.6$ ), $5 \mathrm{mM}$ $\mathrm{MgCl}_{2}, 10 \mathrm{mM} \mathrm{NaCl}$, as described by Loffler et al. (1997), the leukocytes were pelleted and resuspended in $470 \mu \mathrm{l}$ LLB. The subsequent procedure followed the extraction protocol described above.

(iii) Respiratory secretions. Samples were centrifuged at $5000 \mathrm{~g}$ for $10 \mathrm{~min}$. The supernatant was removed and $430 \mu \mathrm{l}$ LLB was added. The extraction was performed as described above.

(iv) Lung biopsies and cornea. Solid material was mechanically disrupted and homogenized in $1 \times$ PBS. The samples were centrifuged at $5000 \mathrm{~g}$ for $10 \mathrm{~min}$, the supernatant was removed and $430 \mu \mathrm{LLB}$ was added. The subsequent steps were as described above.

(v) Bacteria and viruses. For the isolation of DNA from cultured bacteria and virus stocks, a commercially available kit (QIAamp DNA mini kit; Qiagen) was used as recommended by the manufacturer.

Target sequence analysis and primer/probe design. Conserved nucleotide sequences of the fungal ribosomal multi-copy genes (18S, $5.8 \mathrm{~S}$ and 28S) of clinically relevant Aspergillus and Candida species were selected and aligned using the BLAST search software, freely accessible at http://www.ncbi.nlm.nih.gov/BLAST/. Within the $28 \mathrm{~S}$ large ribosomal subunit [between nucleotides 146 and 311 based on the sequence of the $28 \mathrm{~S}$ rDNA gene of $C$. albicans (NCBI accession no. Z48339)], a highly conserved region was identified that spans less than $150 \mathrm{bp}$ in length, thereby optimally fitting the requirements of RQPCR analysis using a hydrolysis TaqMan probe. Sequences for the forward primer, the reverse primer, and the universal probe were selected using Primer Express software (version 2.0; Applied Biosystems) following the manufacturer's guidelines (Table 2). The probe was labelled with FAM (6-carboxyfluorescein) as a reporter molecule at the $5^{\prime}$-end and TAMRA (6-carboxytetramethylrhodamine) as a quencher molecule at the $3^{\prime}$-end (Applied Biosystems). The optimal concentrations for the primers and the probe were assessed by serial analyses both from the functional and economic perspective, and were specified at 400 and $200 \mathrm{nM}$, respectively.

RQ-PCR. PCR reactions were set up in a total volume of $25 \mu \mathrm{l}$ containing $12.5 \mu \mathrm{l}$ universal master mix $[2 \times$ concentration, including ROX-reference dye and uracil $N^{\prime}$-glycosylase (UNG)] (Applied Biosystems), $1 \%$ formamide, a mixture of the forward and the reverse primer (400 $\mathrm{nM}$ each), $200 \mathrm{nM}$ Pan-AC hydrolysis probe, and $5 \mu$ genomic DNA (gDNA).

The mixture was transferred to 96-well optical microtitre plates (Applied Biosystems). Amplification was performed on the ABI 7700 sequence detection system (Applied Biosystems) using the following cycling parameters: $2 \mathrm{~min}$ at $50{ }^{\circ} \mathrm{C}$ (degradation of potentially 
Table 1. GenBank accession numbers of fungal species used for 28S rDNA alignment and selection of sequences targeted by the Pan-AC assay

\begin{tabular}{|ll|}
\hline Name & \multicolumn{1}{|c|}{ NCBI accession no. } \\
\hline A. flavus & $\mathrm{AF} 027863, \mathrm{U} 28899$ \\
A. fumigatus & $\mathrm{AF} 109335, \mathrm{U} 28460, \mathrm{Z} 48340$ \\
A. nidulans & $\mathrm{AF} 109337, \mathrm{U} 29856$ \\
A. niger & $\mathrm{U} 28815, \mathrm{AF} 109344$ \\
A. terreus & $\mathrm{U} 28841, \mathrm{AF} 109340$ \\
A. versicolor & $\mathrm{AF} 433108, \mathrm{AF} 433059$ \\
C. albicans & $\mathrm{Z} 48339, \mathrm{X} 83717, \mathrm{~L} 28817$ \\
C. dubliniensis & $\mathrm{U} 57685, \mathrm{AB} 031020$ \\
C. glabrata & $\mathrm{U} 44808, \mathrm{Z} 48341$ \\
C. guilliermondii & $\mathrm{AF} 374616, \mathrm{U} 45709$ \\
C. kefyr & $\mathrm{AF} 335978, \mathrm{Y} 15476$ \\
C. krusei & $\mathrm{U} 76347, \mathrm{Z} 48567$ \\
C. lipolytica & $\mathrm{AF} 335977$ \\
C. lusitaniae & $\mathrm{U} 44817$ \\
C. parapsilosis & $\mathrm{AF} 374609, \mathrm{Z} 48343$ \\
C. tropicalis & $\mathrm{AF} 267497, \mathrm{Z} 48346$ \\
\hline
\end{tabular}

present contaminating dUTP-containing amplicons by UNG), $10 \mathrm{~min}$ at $95^{\circ} \mathrm{C}$ (inactivation of UNG and activation of AmpliTaq Gold DNA polymerase), followed by 50 cycles of $15 \mathrm{~s}$ at $95{ }^{\circ} \mathrm{C}$ and $60 \mathrm{~s}$ at $60{ }^{\circ} \mathrm{C}$ for target amplification. For absolute quantification of the fungal DNA, standard curves were prepared using serial logarithmic dilutions covering a range of five logs (10 fg-100 pg) gDNA derived from C. albicans and A. fumigatus as positive control samples.

Assessment of the detection limit. To determine the detection limit of fungal pathogens in peripheral blood, $1 \mathrm{ml}$ EDTA-anticoagulated whole blood from healthy volunteer donors was spiked with tenfold serial dilutions of $A$. fumigatus conidia and $C$. albicans cells $\left(10^{5}\right.$ to 1 cell). The number of fungal particles was determined microscopically using a counting chamber. DNA extraction was performed according to the protocol outlined above.

Controls. A number of precautions were undertaken to control the occurrence of false-positive results. Multiple no-template and non-homologous template controls were processed together with the specimens tested, as described previously (Watzinger et al., 2004). To document the efficiency of DNA extraction and amplification, various positive controls were included, as already published (Lion, 2001). In clinical samples containing human cells, a single-copy housekeeping gene ( $\beta 2$-microglobulin) was co-amplified in parallel with the fungal targets (Lion, 2001). For largely cell-free human specimens, defined concentrations of a seal herpes virus were spiked into the sample prior to DNA extraction and analysed by RQ-PCR to control for the potential occurrence of inhibitory effects (Watzinger et al., 2004).

\section{RESULTS AND DISCUSSION}

In the present report, a RQ-PCR assay is described permitting the detection and quantification of a broad range of clinically relevant Aspergillus and Candida species (Table 1) in a single

\begin{tabular}{|c|c|}
\hline NCBI acc.no. & Species \\
\hline U28889 & A. flavis \\
\hline $\mathrm{U} 28460$ & A. fumigatus \\
\hline U29859 & A. nidulans* \\
\hline U28817 & A. niger \\
\hline $\mathrm{U} 28845$ & A. terreus \\
\hline A.F454195 & A. versicolor \\
\hline 248339 & C. albicans \\
\hline U57685 & C. dubliniensis \\
\hline $\mathrm{U} 44808$ & c. glabrata \\
\hline AF374616 & c. guilitiermondii* \\
\hline AF335978 & c. kef $\mathrm{Yz}^{*}$ \\
\hline U76347 & C. krusei* \\
\hline A.F335977 & c. Iipolytica* \\
\hline U44817 & c. 2usitaniat* \\
\hline AF374609 & c. parapsizasis \\
\hline AF267497 & c. tropicalis \\
\hline
\end{tabular}

M11167 Human 285 rib. gene

U13369 Humen ribosomal DNA

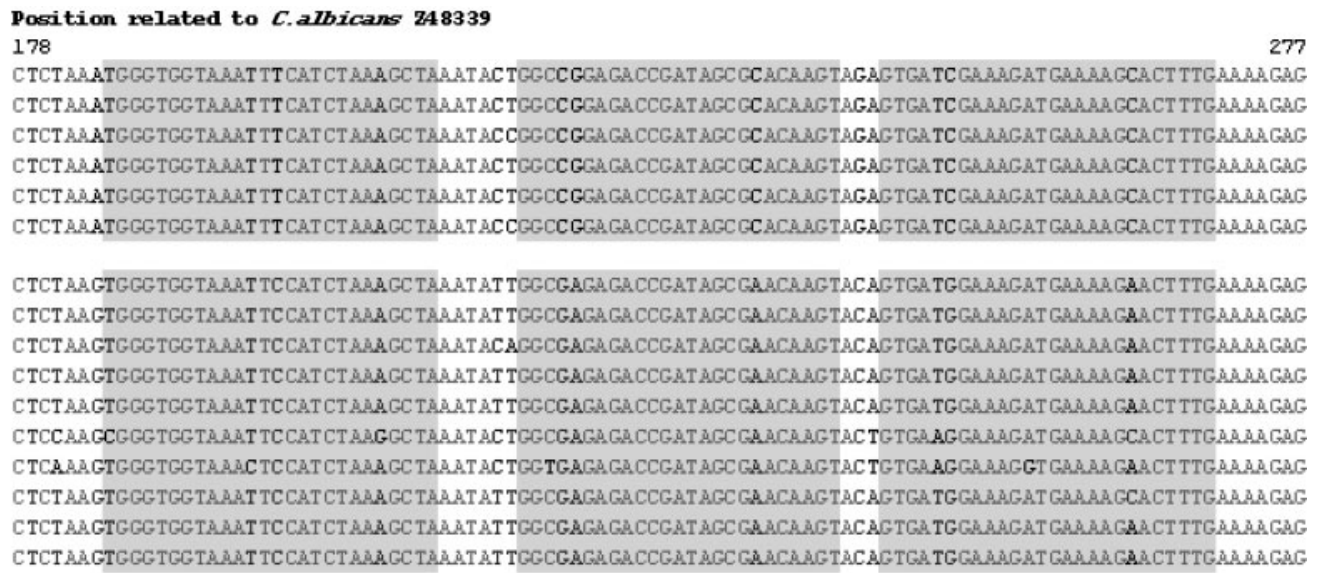



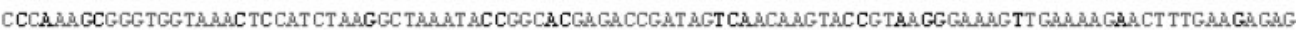

\begin{tabular}{|c|c|c|c|c|}
\hline \multirow{2}{*}{\multicolumn{2}{|c|}{ TGGGTGGTAAAT TYCATCTAARGCTA }} & 217 & 241 & 270 \\
\hline & & \multicolumn{2}{|c|}{ CCGSYCTCT GGCTATCGCKTGT TCA } & CACTUSCT TTC TACTT TT CKT GA.AAC \\
\hline $5^{\prime}$ & $3^{\prime}$ & 3 & $5^{\prime}$ & $5^{\prime}$ \\
\hline
\end{tabular}

Wobble positions used: $\mathrm{Y}=\mathrm{C}$ or $\mathrm{T} ; \mathrm{R}=\mathrm{G}$ or $\mathrm{A} ; \mathrm{S}=\mathrm{G}$ or $\mathrm{C} ; \mathrm{K}=\mathrm{G}$ or $\mathrm{T} ; \mathrm{W}=\mathrm{A}$ or $\mathrm{T}$

Fig. 1. Alignment of a highly conserved region within the $28 \mathrm{~S}$ rDNA gene of six Aspergillus species, ten Candida species and the corresponding region from the human genome. The primer pair and the probe (grey boxes) for the Pan-AC RQ-PCR assay were placed within this region. The indicated nucleotide positions refer to the sequence of $C$. albicans (NCBI accession no. Z48339). The asterisks indicate species that are listed under another name in the NCBI database: $A$. nidulans=NCBI Emericella nidulans; C. guilliermondii=NCBI Pichia guilliermondii; C. kefyr=NCBI Kluyveromyces marxianus; C. kruse $=\mathrm{NCBI}$ Issatschenkia orientalis; C. lipolytica=NCBI Yarrowia lipolytica; C. Iusitaniae=NCBI Clavispora lusitaniae. 
Table 2. Primers and probe in the Pan-AC RQ-PCR assay

\begin{tabular}{|c|c|c|c|c|c|}
\hline Sample & Oligonucleotide sequence $\left(5^{\prime}-3^{\prime}\right)$ & Target & $\begin{array}{c}\text { NCBI accession } \\
\text { no. }\end{array}$ & $\begin{array}{l}\text { Nucleotide } \\
\text { position }^{\star}\end{array}$ & Concn $(\mathrm{nM})$ \\
\hline Fw primer & TGGGTGGTAAATTYCATCTAAAGCTA & C. albicans & Z48339 & $185-210$ & 400 \\
\hline Rev primer & CAAGTKCTTTTCATCTTTCSWTCAC & C. albicans & Z48339 & $245-270$ & 400 \\
\hline Probe (rev) & ACTTGTKCGCTATCGGTCTCYSGCC & C. albicans & Z48339 & $217-241$ & 200 \\
\hline
\end{tabular}

${ }^{*}$ Nucleotide positions correspond to the NCBI sequence, accession no. Z48339.

reaction. A single primer pair and a universal probe were designed within a highly conserved region of the $28 \mathrm{~S}$ large ribosomal subunit (Fig. 1). The selected primer and probe sequences display a degenerated code (Table 2), which was a prerequisite for sensitive detection of fungal species differing from others at single nucleotide positions.

\section{Specificity of the Pan-AC assay}

The ability of the Pan-AC system to detect all fungus species of interest was determined by testing DNA derived from cultures of reference strains, including C. albicans, C. glabrata, C. krusei, C. tropicalis, C. parapsilosis, C. guilliermondii, C. kefyr, Candida lipolytica, C. lusitaniae, $C$. dubliniensis, A. fumigatus, A. flavus, A. niger, A. terreus, A. versicolor and $A$. nidulans. Target sequences of all species were amplified successfully and showed nearly identical amplification efficiencies (data not shown). Based on the sequence alignment of additional, less common Aspergillus and Candida species, the Pan-AC RQ-PCR assay can be expected to cover several other members of these two genera with similar sensitivity.

The Pan-AC primers and probe were evaluated for possible cross-reactivity with bacterial or viral pathogens, both by sequence alignment using the BLAST software, and experimentally by testing the Pan-AC assay against bacterial and viral DNA from different organisms (see Methods). No crossreactivity between the Pan-AC primer/probe detection system and non-fungal pathogens was observed (data not shown). As indicated in Fig. 1, DNA sequences from different human genes show significant homology with the fungal DNA sequence targeted by the Pan-AC assay. Analysing human DNA extracted from peripheral blood of healthy volunteer donors initially revealed some degree of crossreactivity. Different chemicals, including DMSO, glycerol and formamide, were tested in different concentrations (1-5\%) to increase the stringency of the PCR reaction without simultaneously compromising the overall amplification efficiency. DMSO and glycerol completely inhibited the PCR reaction even at low concentrations (data not shown). By contrast, formamide concentrations of $1 \%$ abrogated the cross-reactivity with human DNA, while maintaining the high amplification efficiency of the PCR assay (Table 3). This concentration of formamide was, therefore, included both in the assessment of the detection limit and the testing of clinical specimens by the Pan-AC assay.

\section{Detection limit of the assay}

The detection limit of the Pan-AC assay was determined by testing serial dilutions of fungal gDNA derived from organisms representing yeasts (C. albicans) and moulds (A. fumigatus). The DNA concentration of the two fungal species was determined by fluorometric measurements, and serial logarithmic dilutions across a range of five logs $(10 \mathrm{fg}$ $-100 \mathrm{pg}$ ) were prepared. After PCR amplification, the cycle threshold $\left(\mathrm{C}_{\mathrm{T}}\right)$ values of individual dilutions steps were plotted against the template amount, leading to typical standard curves (Fig. 2). The $y$ intercept, which corresponds to the theoretical limit of detection, was determined at $\mathrm{C}_{\mathrm{T}}$ 38.9 for $A$. fumigatus and $\mathrm{C}_{\mathrm{T}} 37.9$ for $C$. albicans. In view of the inter-assay variability of the technique in the range of $\pm 1 \mathrm{C}_{\mathrm{T}}$, this difference can be regarded as minor. The amplification efficiencies of the Candida and Aspergillus species listed in Table 1 revealed only marginal differences (data not shown). The standard curves presented are, therefore, applicable in quantitative analysis of all fungal species covered by the Pan-AC assay. The lowest template amount permitting accurate and reproducible quantification of fungal DNA was in the order of $10 \mathrm{fg}$.

In order to investigate the applicability of the Pan-AC assay to the analysis of clinical specimens, peripheral blood from

Table 3. Influence of formamide concentration on the $\mathrm{C}_{\mathrm{T}}$ and the fluorescence intensity of the reporter $(\Delta \mathrm{Rn})$

The effect of formamide was tested for different fungal DNA template concentrations of both Candida and Aspergillus representatives ranging from $1 \mathrm{pg}$ to $10 \mathrm{fg}$. The RQ-PCR results shown represent the effect of formamide observed at the lowest fungal template concentration tested (10 fg C. albicans DNA). Although the overall fluorescence intensity decreased with rising concentrations of formamide, the concentration at which any cross-reactivity with human DNA was abrogated (1\%) generally revealed only slightly increased $\mathrm{C}_{\mathrm{T}}$ values.

\begin{tabular}{|lcc|}
\hline Formamide concn (\%) & $\mathbf{C}_{\mathbf{T}}$ value & $\boldsymbol{\Delta R \mathbf { n }}$ \\
\hline 0 & 33.60 & 2.41 \\
0.5 & 34.17 & 1.72 \\
1 & 34.12 & 1.55 \\
1.5 & 35.46 & 1.10 \\
2 & 36.61 & 0.95 \\
2.5 & 40.86 & 0.50 \\
\hline
\end{tabular}



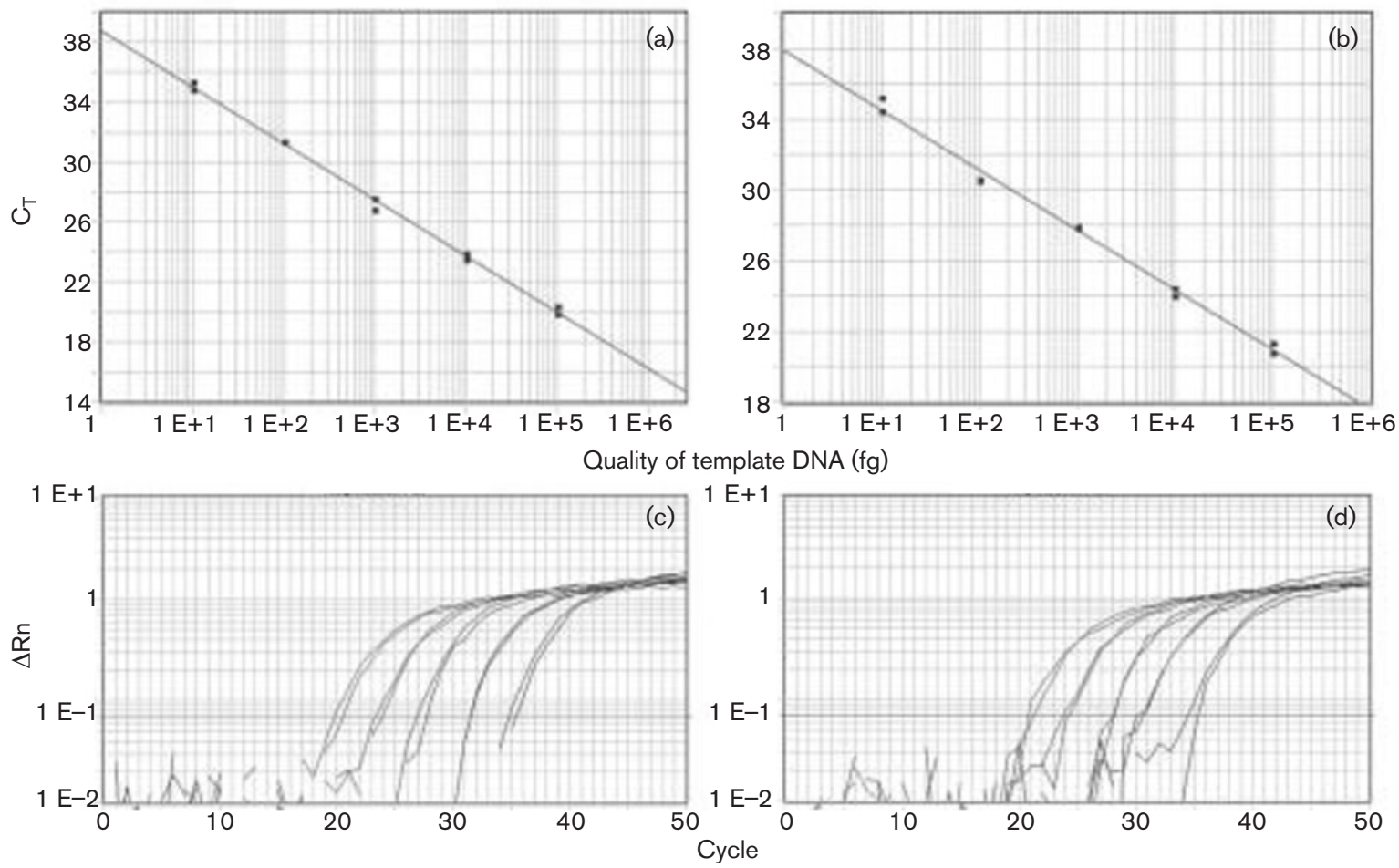

Fig. 2. Standard curves $(a, b)$ and amplification plots $(c, d)$ based on serial dilutions of fungal gDNA ranging from 10 fg to $100 \mathrm{pg}$, derived from representatives of moulds (A. fumigatus) $(\mathrm{a}, \mathrm{c})$ and yeasts (C. albicans) $(\mathrm{b}, \mathrm{d})$. The assays underlying the generation of standard curves were performed in duplicate.

healthy volunteer donors was spiked with tenfold serial dilutions of A. fumigatus conidia and C. albicans cells, covering a range between $10^{5}$ to 1 organism $\mathrm{ml}^{-1}$. The DNA was extracted and amplified as described in Methods. In patients with IFI, the fungal load in peripheral blood samples is generally low, often below 10 c.f.u. $\mathrm{ml}^{-1}$ (Loeffler et al., 2000). Based on these observations, the sensitivity of the PCR assay is crucial for the detection and quantification of fungal pathogens. The detection limit of the Pan-AC assay in spiking experiments was less than 10 organisms per PCR reaction; however, for reproducible detection and quantitative analysis a higher volume of peripheral blood providing larger overall number of fungal organisms was beneficial (data not shown).

\section{Analysis of clinical specimens}

The Pan-AC assay was employed to investigate specimens from 17 haemato-oncological or intensive care patients with fungal infections diagnosed by other methodological approaches, including primarily culture techniques and DNA sequencing. According to the EORTC criteria, 4 patients were classified as having a possible IFI and 12 patients a probable IFI infection (Table 4, samples 1-16). Only for the patient from whom the cornea specimen was derived, was no EORTC classification available (Table 4 , sample 17).
The Pan-AC assay revealed positive results in the clinical specimens studied, including lung biopsies of patients with pulmonary aspergillosis or candidiasis, peripheral blood specimens from patients with different types of candidaemia, and respiratory secretions positive for different Aspergillus species (Table 4). In one of the latter specimens, co-infection with $C$. lusitaniae was detected (Table 4 , sample 13). The only clinical sample that tested negative by the Pan-AC assay was a cornea specimen, in which culture analysis revealed the presence of $F$. solanii. This specimen only served as a control because this fungus is not within the detection spectrum of the PCR assay presented (Table 4). Quantitative analysis of the fungal load in specimens positive by RQ-PCR was performed by using the appropriate standard curves, and the amount of fungal DNA determined was translated to the number of organisms on the basis of the estimated mean genome masses of Aspergillus and Candida species of 32 and $37 \mathrm{fg}$, respectively.

\section{Prevention and control of contamination}

A major problem of fungal PCR assays is the high risk of contamination (Loeffler et al., 1999), which is attributable to the ubiquitous presence of airborne fungal spores, and traces of fungal DNA in a variety of reagents and other consumables. To avoid false-positive results, it is imper- 
Table 4. Fungal species identified in clinical specimens

\begin{tabular}{|c|c|c|c|c|c|c|c|}
\hline Sample & Source & $\begin{array}{c}\text { Diagnosis of } \\
\text { IFI }^{\star}\end{array}$ & Microbiological evidence & Sequencing & Pan-AC PCR & $\mathrm{C}_{\mathrm{T}}$ & $\begin{array}{c}\text { Fungal DNA } \\
(\text { fg }) \dagger\end{array}$ \\
\hline 1 & Blood & Probable & C. glabrata & $\mathrm{ND}$ & Positive & 34.8 & 8 \\
\hline 2 & Blood & Possible & $\mathrm{ND}$ & C. albicans & Positive & 28.1 & 600 \\
\hline 3 & Blood & Possible & ND & C. krusei & Positive & 37.0 & 2 \\
\hline 4 & Lung biopsy & Possible & ND & A. fumigatus & Positive & 35.7 & 4 \\
\hline 5 & Lung biopsy & Possible & ND & C. lipolytica & Positive & 30.7 & 130 \\
\hline 6 & Respiratory tract & Probable & A. fumigatus, A. niger & ND & Positive & 27.2 & 1429 \\
\hline 7 & Respiratory tract & Probable & A. fumigatus & ND & Positive & 32.4 & 40 \\
\hline 8 & Respiratory tract & Probable & A. fumigatus & $\mathrm{ND}$ & Positive & 31.6 & 69 \\
\hline 9 & Respiratory tract & Probable & A. fumigatus & $\mathrm{ND}$ & Positive & 26.1 & 2885 \\
\hline 10 & Respiratory tract & Probable & A. fumigatus & $\mathrm{ND}$ & Positive & 29.8 & 246 \\
\hline 11 & Respiratory tract & Probable & A. nidulans & ND & Positive & 32.4 & 40 \\
\hline 12 & Respiratory tract & Probable & A. fumigatus, A. flavus & $\mathrm{ND}$ & Positive & 29.9 & 230 \\
\hline 13 & Respiratory tract & Probable & A. fumigatus, C. lusitaniae & $\mathrm{ND}$ & Positive & 35.7 & 4 \\
\hline 14 & Respiratory tract & Probable & Aspergillus spp. & ND & Positive & 33.5 & 19 \\
\hline 15 & Respiratory tract & Probable & A. fumigatus & $\mathrm{ND}$ & Positive & 32.5 & 40 \\
\hline 16 & Respiratory tract & Probable & A. fumigatus & ND & Positive & 31.5 & 78 \\
\hline 17 & Cornea & - & F. solanii & ND & Negative & - & - \\
\hline
\end{tabular}

ND, Not determined.

*The diagnosis of IFI was performed according to the EORTC criteria (http://www.doctorfungus.org/lecture/eortc_msg_rev06.htm).

$\dagger$ The numbers indicate the determined amount of fungal DNA at the beginning of the PCR-reactions. To calculate the fungal load in the clinical specimen investigated, the quantity of fungal DNA in fg assessed by RQ-PCR analysis can be translated to the number of fungal organisms on the basis of the estimated genome mass and the appropriate dilution factor of the sample analysed.

ative therefore to control all materials used, both self-made and commercially available, for fungal contaminants, and to include multiple negative controls in each assay. The fungus detection assays must be performed under adequate experimental conditions, which include the preparation of reagents and processing of clinical samples under a laminar flow biohazard hood. With appropriate precautions and controls, the RQ-PCR assay presented can serve as a reliable diagnostic tool for the detection and quantitative monitoring of pathogenic fungi in clinical specimens.

In view of its broad specificity, the Pan-AC assay could serve as a screening technique for the presence of IFI. In patients testing positive, antifungal agents, such as voriconazole or caspofungins, could be used as first-line treatment, because these substances can be expected to cover the entire range of fungi detected by this assay. The use of agents with a narrower spectrum of antifungal activity, such as fluconazole or amphotericin $\mathrm{B}$, would require the identification of the fungal species present, which can be performed by a number of molecular techniques, including, for example, the analysis of the variable ITS2 region or species-specific hybridization (Chen et al., 2000; Elie et al., 1998; Sandhu et al., 1995; Turenne et al., 1999).

In comparison to most earlier RQ-PCR approaches to the detection of invasive aspergillosis or candidiasis ( $\mathrm{Bu}$ et al., 2005; Buchheidt et al., 2004; Kami et al., 2001; Kasai et al., 2006; Klingspor \& Jalal, 2006; Spiess et al., 2003), the PanAC assay covers a considerably larger spectrum of pathogenic Aspergillus and Candida species in a single reaction, using a universal detection probe and a single primer pair. Our data indicate that the Pan-AC assay can be readily implemented in routine clinical diagnosis and monitoring of the majority of IFIs.

\section{NOTE ADDED IN PROOF}

While this paper was in press, a paper by SchabereiterGurtner et al. (2007) was published, in which a similar technique is described.

\section{ACKNOWLEDGEMENTS}

The study was supported by the Austrian Science Fund (grant no. P16929-B13). We are grateful to Birgit Willinger for providing us with clinical material from proven fungal infections.

\section{REFERENCES}

Beck-Sagué, C. M. \& Jarvis, W. R. (1993). Secular trends in the epidemiology of nosocomial fungal infection in the United States, 1980-1990. National Nosocomial Infections Surveillance System. J Infect Dis 167, 1247-1251.

Bille, J., Marchetti, O. \& Calandra, T. (2005). Changing face of healthcare associated fungal infections. Curr Opin Infect Dis 18, 314-319.

Bu, R., Sathiapalan, R. K., Ibrahim, M. M., Al-Mohsen, I., Almodavar, E., Gutierrez, M. I. \& Bhatia, K. (2005). Monochrome LightCycler PCR 
assay for detection and quantification of five common species of Candida and Aspergillus. J Med Microbiol 54, 243-248.

Buchheidt, D., Hummel, M., Schleiermacher, D., Spiess, B. \& Hehlmann, R. (2004). Current molecular diagnostic approaches to systemic infections with Aspergillus species in patients with hematological malignancies. Leuk Lymphoma 45, 463-468.

Chen, Y. C., Eisner, J. D., Kattar, M. M., Rassoulian-Barrett, S. L., LaFe, K., Yarfitz, S. L., Limaye, A. P. \& Cookson, B. T. (2000). Identification of medically important yeasts using PCR-based detection of DNA sequence polymorphisms in the internal transcribed spacer 2 region of the rRNA genes. J Clin Microbiol 38, 2302-2310.

Chryssanthou, E., Andersson, B., Petrini, B., Lofdahl, S. \& Tollemar, J. (1994). Detection of Candida albicans DNA in serum by polymerase chain reaction. Scand J Infect Dis 26, 479-485.

Coleman, D. C., Rinaldi, M. G., Haynes, K. A., Rex, J. H., Summerbell, R. C., Anaissie, E. J., Li, A. \& Sullivan, D. J. (1998). Importance of Candida species other than Candida albicans as opportunistic pathogens. Med Mycol 36 (Suppl. 1), 156-165.

Costa, C., Vidaud, D., Olivi, M., Bart-Delabesse, E., Vidaud, M. \& Bretagne, S. (2001). Development of two real-time quantitative TaqMan PCR assays to detect circulating Aspergillus fumigatus DNA in serum. J Microbiol Methods 44, 263-269.

Costa, C., Costa, J. M., Desterke, C., Botterel, F., Cordonnier, C. \& Bretagne, S. (2002). Real-time PCR coupled with automated DNA extraction and detection of galactomannan antigen in serum by enzyme-linked immunosorbent assay for diagnosis of invasive aspergillosis. J Clin Microbiol 40, 2224-2227.

Denning, D. W. (1998). Invasive aspergillosis. Clin Infect Dis 26, 781-803.

Duthie, R. \& Denning, D. W. (1995). Aspergillus fungemia: report of two cases and review. Clin Infect Dis 20, 598-605.

Einsele, H., Hebart, H., Roller, G., Loffler, J., Rothenhofer, I., Muller, C. A., Bowden, R. A., van Burik, J., Engelhard, D. \& other authors (1997). Detection and identification of fungal pathogens in blood by using molecular probes. J Clin Microbiol 35, 1353-1360.

Elie, C. M., Lott, T. J., Reiss, E. \& Morrison, C. J. (1998). Rapid identification of Candida species with species-specific DNA probes. J Clin Microbiol 36, 3260-3265.

Goodrich, J. M., Reed, E. C., Mori, M., Fisher, L. D., Skerrett, S., Dandliker, P. S., Klis, B., Counts, G. W. \& Meyers, J. D. (1991). Clinical features and analysis of risk factors for invasive candidal infection after marrow transplantation. J Infect Dis 164, 731-740.

Jordan, J. A. (1994). PCR identification of four medically important Candida species by using a single primer pair. J Clin Microbiol 32, 2962-2967.

Jordanides, N. E., Allan, E. K., McLintock, L. A., Copland, M., Devaney, M., Stewart, K., Parker, A. N., Johnson, P. R., Holyoake, T. L. \& Jones, B. L. (2005). A prospective study of real-time panfungal PCR for the early diagnosis of invasive fungal infection in haematooncology patients. Bone Marrow Transplant 35, 389-395.

Kami, M., Fukui, T., Ogawa, S., Kazuyama, Y., Machida, U., Tanaka, Y., Kanda, Y., Kashima, T., Yamazaki, Y. \& other authors (2001). Use of real-time PCR on blood samples for diagnosis of invasive aspergillosis. Clin Infect Dis 33, 1504-1512.

Kasai, M., Francesconi, A., Petraitiene, R., Petraitis, V., Kelaher, A. M., Kim, H. S., Meletiadis, J., Sein, T., Bacher, J. \& Walsh, T. J. (2006). Use of quantitative real-time PCR to study the kinetics of extracellular DNA released from Candida albicans, with implications for diagnosis of invasive candidiasis. J Clin Microbiol 44, 143-150.

Klingspor, L. \& Jalal, S. (2006). Molecular detection and identification of Candida and Aspergillus spp. from clinical samples using real-time PCR. Clin Microbiol Infect 12, 745-753.
Lion, T. (2001). Current recommendations for positive controls in RT-PCR assays. Leukemia 15, 1033-1037.

Loeffler, J., Hebart, H., Bialek, R., Hagmeyer, L., Schmidt, D., Serey, F. P., Hartmann, M., Eucker, J. \& Einsele, H. (1999). Contaminations occurring in fungal PCR assays. J Clin Microbiol 37, 1200-1202.

Loeffler, J., Henke, N., Hebart, H., Schmidt, D., Hagmeyer, L., Schumacher, U. \& Einsele, H. (2000). Quantification of fungal DNA by using fluorescence resonance energy transfer and the light cycler system. J Clin Microbiol 38, 586-590.

Loffler, J., Hebart, H., Schumacher, U., Reitze, H. \& Einsele, H. (1997). Comparison of different methods for extraction of DNA of fungal pathogens from cultures and blood. J Clin Microbiol 35, 3311-3312.

Maaroufi, Y., De Bruyne, J. M., Duchateau, V., Georgala, A. \& Crokaert, F. (2004). Early detection and identification of commonly encountered Candida species from simulated blood cultures by using a real-time PCR-based assay. J Mol Diagn 6, 108-114.

Medlin, L., Elwood, H. J., Stickel, S. \& Sogin, M. L. (1988). The characterization of enzymatically amplified eukaryotic 16S-like rRNA-coding regions. Gene 71, 491-499.

Morace, G., Sanguinetti, M., Posteraro, B., Lo, C. G. \& Fadda, G. (1997). Identification of various medically important Candida species in clinical specimens by PCR-restriction enzyme analysis. J Clin Microbiol 35, 667-672.

Pfeiffer, C. D., Fine, J. P. \& Safdar, N. (2006). Diagnosis of invasive aspergillosis using a galactomannan assay: a meta-analysis. Clin Infect Dis 42, 1417-1427.

Sandhu, G. S., Kline, B. C., Stockman, L. \& Roberts, G. D. (1995). Molecular probes for diagnosis of fungal infections. J Clin Microbiol 33, 2913-2919.

Schabereiter-Gurtner, C., Selitsch, B., Rotter, M. L., Hirschl, A. M. \& Willinger, B. (2007). Development of novel real-time PCR assays for detection and differentiation of eleven medically important Aspergillus and Candida specimens. J Clin Microbiol 45, 906-914.

Singh, N. (2001). Trends in the epidemiology of opportunistic fungal infections: predisposing factors and the impact of antimicrobial use practices. Clin Infect Dis 33, 1692-1696.

Spiess, B., Buchheidt, D., Baust, C., Skladny, H., Seifarth, W., Zeilfelder, U., Leib-Mosch, C., Morz, H. \& Hehlmann, R. (2003). Development of a LightCycler PCR assay for detection and quantification of Aspergillus fumigatus DNA in clinical samples from neutropenic patients. J Clin Microbiol 41, 1811-1818.

Torres, H. A., Rivero, G. A., Lewis, R. E., Hachem, R., Raad, I. I. \& Kontoyiannis, D. P. (2003). Aspergillosis caused by non-fumigatus Aspergillus species: risk factors and in vitro susceptibility compared with Aspergillus fumigatus. Diagn Microbiol Infect Dis 46, 25-28.

Turenne, C. Y., Sanche, S. E., Hoban, D. J., Karlowsky, J. A. \& Kabani, A. M. (1999). Rapid identification of fungi by using the ITS2 genetic region and an automated fluorescent capillary electrophoresis system. J Clin Microbiol 37, 1846-1851.

Vincent, J. L., Anaissie, E., Bruining, H., Demajo, W., el Ebiary, M., Haber, J., Hiramatsu, Y., Nitenberg, G., Nystrom, P. O. \& other authors (1998). Epidemiology, diagnosis and treatment of systemic Candida infection in surgical patients under intensive care. Intensive Care Med 24, 206-216.

Watzinger, F., Suda, M., Preuner, S., Baumgartinger, R., Ebner, K., Baskova, L., Niesters, H. G., Lawitschka, A. \& Lion, T. (2004). Realtime quantitative PCR assays for detection and monitoring of pathogenic human viruses in immunosuppressed pediatric patients. J Clin Microbiol 42, 5189-5198.

White, P. L., Shetty, A. \& Barnes, R. A. (2003). Detection of seven Candida species using the Light-Cycler system. J Med Microbiol 52, 229-238. 